\title{
The prevalence of back and leg pain and the cross-sectional association with adverse health outcomes in community dwelling older adults in England
}

Esther Williamson $\mathrm{PhD}^{1}$, Maria T Sanchez-Santos $\mathrm{MSc}^{1}$, Alana Morris $\mathrm{MSc}^{1}$, Angela Garrett ${ }^{1}$, Oliver Conway BA (Hons) ${ }^{1}$, Graham Boniface MRes ${ }^{1}$, Jeremy Fairbank MD FRCS ${ }^{1}$ and Sarah E Lamb DPhil ${ }^{1,2}$

\section{Authors' affiliations:}

${ }^{1}$ Nuffield Department of Rheumatology, Orthopaedics and Musculoskeletal Sciences, University of

Oxford

${ }^{2}$ College of Medicine and Health, University of Exeter, Exeter, United Kingdom.

Corresponding Author: Esther Williamson

Nuffield Department of Orthopaedics, Rheumatology and

Musculoskeletal Sciences,

University of Oxford,

Windmill Road, Headington,

Oxford, OX3 7LD, UK

Tel: +44(0)1865223120

Email: esther.williamson@ndorms.ox.ac.uk

Funding acknowledgements: This research was funded by the National Institute of Health Research (NIHR) Programme Grants for Applied Research (reference: PTC-RP-PG-0213-20002). It was supported by the NIHR Applied Research Collaboration (ARC) Oxford and Thames Valley at Oxford Health NHS Foundation Trust and the NIHR Biomedical Research Centre, Oxford. MS is funded by the NIHR Biomedical Research Centre, Oxford. The views expressed in this publication are those of the authors and not necessarily those of the NIHR or the Department of Health and Social Care.

Research ethics committee: The London - Brent Research Ethics Committee (16/LO/0348) approved this study on the 10th March 2016. 


\section{Abstract}

Study Design: Cross-sectional analysis of the Oxford Pain, Activity and Lifestyle (OPAL) Cohort Study Summary of background data: Epidemiological data describing the prevalence of back pain (BP) and leg pain in older adults in England is lacking.

Objective: To assess the prevalence of BP and leg pain and determine their relationship with adverse health states among older adults in England.

Methods: 5,304 community-dwelling adults (aged 65-100 years) enrolled in the OPAL cohort study who provided data on BP and leg pain were included. Participants were classified into four groups based on reports of back and leg pain: 1) no BP, 2) BP only, 3) BP and leg pain which was likely to be neurogenic claudication (NC), 4) and BP and leg pain which was not NC. Adverse health states were frailty, falls, mobility decline, low walking confidence, poor sleep quality and urinary incontinence. We collected demographic and socioeconomic information, health-related quality of life and existing health conditions, and estimated the association between BP presentations and adverse health states using regression analysis.

Results: Thirty-four percent of participants $(1,786 / 5,304)$ reported BP only, $11.2 \%$ ( $n=594 / 5,304)$ reported BP and NC and 8.3\% ( $n=441 / 5,304)$ reported BP and non-NC leg pain. Participants with BP had worse quality of life compared to those without BP. All BP presentations were significantly associated with adverse health states. Those with NC were most affected. In particular, there was greater relative risk (RR) of low walking confidence (RR 95\% Cl 3.11 [2.56-3.78]), frailty ( $R R$ 95\% $\mathrm{Cl} 1.88$ [1.67-2.11]) and mobility decline (RR 95\% CI 1.74 [1.54-1.97]) compared to no BP.

Conclusion: Back and leg pain is a common problem for older adults and associated with reduced quality of life and adverse health states. Findings suggest a need to develop more effective treatment for older adults with back pain especially for those with neurogenic claudication.

Key words (10-15): Older adults, Back pain, leg pain, neurogenic claudication, spinal stenosis, adverse health states, frailty, falls, mobility decline 
Level of Evidence: Level 2 
Key Points.

- Back and leg pain is a common problem for community dwelling older adults and for many it is a long-standing problem with few reporting an improving clinical picture especially for participants with symptoms of neurogenic claudication.

- Older adults with back and leg pain report lower health related quality of life and the worst quality of life was reported by participants with neurogenic claudication.

- The report of back and leg pain is associated with adverse health states including frailty, falls and mobility decline compared to no report of back pain.

- Participants reporting symptoms of neurogenic claudication represented the greatest proportion of respondents reporting two or more adverse health states and the strongest associations were with mobility related adverse outcomes.

- There is a need to develop more effective treatment for older adults with back and leg pain, especially, for those with neurogenic claudication. 
Mini Abstract/Précis.

This study investigated the prevalence of back and leg pain in older adults and the association with adverse health states including frailty, falls and immobility. The report of back and leg pain was associated with adverse health states. The associations were strongest in participants reporting neurogenic claudication. 
Word count $=3058$

\section{Introduction}

In the United Kingdom (UK), approximately one quarter of older adults suffer from back pain (BP). ${ }^{1,2}$ Older adults may also experience leg pain referred from the lumbar spine of which neurogenic claudication (NC) due to spinal stenosis is a common cause. ${ }^{3} \mathrm{NC}$ is the most common reason that older adults undergo spinal surgery. ${ }^{4}$ It is estimated that $11 \%$ of community dwelling older adults report symptoms of $\mathrm{NC}$, but there are no estimates from community dwelling UK populations. ${ }^{5} \mathrm{~A}$ single UK based study $(n=30)$ estimated the prevalence of NC amongst patients (50 years and over) presenting with back and leg pain to primary care to be $87 \%{ }^{6}$

Little is also known about the relationship between BP and different patterns of leg pain and adverse health states including frailty, mobility decline, falls, poor sleep quality and incontinence. BP in older adults is associated with frailty, falls and immobility. ${ }^{7-11} \mathrm{BP}$ and leg pain have been associated with falls and functional difficulties but studies are limited in this area. ${ }^{12}$ To the best of our knowledge, no studies have investigated the association between BP and different patterns of leg pain with adverse health states. It is unknown if individuals with certain presentations (leg pain consistent with neurogenic claudication versus leg pain which is not neurogenic claudication) are more likely to report adverse health states. Improving our understanding of the presentations of BP and leg pain in older adults has the potential to help develop more effective interventions. Therefore, the aims of this study are to 1) describe the prevalence of BP and leg pain in a cohort of community dwelling older adults in England and 2) estimate the association between BP and leg pain presentations and adverse health states. 


\section{Materials and methods}

\section{Study design and participants}

The Oxford Pain, Activity and Lifestyle (OPAL) cohort study is a prospective cohort study of community dwelling older adults in England, UK. We sampled people (65 years and over) from 35 general practices in England. Each practice selected a random sample of 400 community dwelling practice registrants stratified by age (65-74 years, $\geq 75$ years). Between June 2016 and August 2018, general practices invited 12,839 patients to participate in this study. Potential participants received an information leaflet consent form and baseline questionnaire. Those who returned a completed consent form and questionnaire to the study office were enrolled in the study. Forty-two percent $(5,409 / 12,839)$ of individuals invited were enrolled in the study. Ninety-eight percent of cohort study participants $(5,304 / 5,409)$ provided data on back and leg pain and were included in this analysis.

\section{Ethical approval}

The London - Brent Research Ethics Committee (16/LO/0348) approved this study on the 10th March 2016.

\section{Data collection and definition of variables}

Dependent variables: adverse health states

The Tilburg Frailty Indicator is a multidimensional self-reported measure of frailty and consists of three domains (physical, psychological and social) providing a total score out of $15 \cdot{ }^{13,14}$ A score of $\geq 5$ identifies an individual as frail. ${ }^{13}$ Mobility decline was assessed by asking: "Compared to one year ago, how would you rate your walking in general?" using a 5-point scale constructed for the study. Participants reporting worsening of walking was classified as having mobility decline. Participants rated their confidence to walk half a mile using a question from the Modified Gait Self-efficacy Scale. ${ }^{15}$ Falls in the last year were collected using Prevention of Falls Network Europe recommendations by asking, "In the last 12 months, have you had any fall including a slip or trip following which you have come to rest on the ground, floor or lower level?".$^{16}$ Incontinence was reported using the urinary 
incontinence item from the Barthel Index. ${ }^{17,18}$ Participants reported frequency of urinary incontinence who selected never or less than once per week were considered continent and the remaining participants were considered incontinent. Participants rated their sleep quality (very good, fairly good, fairly bad or very bad) during the past month using the sleep quality overall rating from Pittsburgh Sleep Quality Index..$^{19}$ Participants who reported fairly bad or very bad sleep quality were classified as 'poor sleep quality'.

\section{Independent variable: Back and leg pain}

Participants were asked if they were troubled by BP or related symptoms. If 'yes', the participant was asked about frequency (every day, most days, some days, few days, rarely), troublesomeness (intensity) (extremely, very, moderately, slightly, not at all) ${ }^{20}$ and spread into the legs over the last 6 weeks. They were asked about the age when they were first troubled by BP (onset) and its pattern since onset (getting better, getting worse, fairly constant, come and goes over time). NC is defined as the presence of BP or other symptoms that travel from the back into the buttocks or legs, and are worse when standing and/or walking and better when sitting and/or bending. ${ }^{21}$ Using this definition, participants reporting leg pain made worse by standing or walking and made better with sitting or bending were classified as having leg pain likely to be NC. ${ }^{21}$ The questions used to identify those with NC are commonly used in clinical practice and been shown to have high sensitivity and specificity to identify people with symptoms arising from spinal stenosis. ${ }^{21}$

We divided the sample into four mutually exclusive groups:

1. No BP (reference category)

2. BP only

3. BP and NC

4. BP and leg pain that is not NC (non-NC) 


\section{Covariates}

Demographic factors included age, sex and education. Self-reported height and weight were used to calculate Body Mass Index (BMI). Socioeconomic status was determined using the Index of Multiple Deprivation (IMD) (0-100 score) based on the participant's postcode. ${ }^{22} \mathrm{~A}$ higher score indicates greater deprivation. Due to skewed distribution of the IMD score, we divided it into four categories based on the standard deviation (SD) of the OPAL sample: Category-1 (0 to 1-SD; reference category (most affluent)), Category-2 (1 to 2 SD), Category-3 (2 to 3 SD) and Category-4 ( $\geq 3$ SD). A SD of 14.11 was used.

Participants were classified as ex/current smokers or never smoked. ${ }^{23}$ Participants rated the physical demands of their main occupation during their life which was classified as very light/light, moderate and strenuous/very strenuous.

Participants indicated if their doctor or nurse had told them that they had any of the following health conditions: arthritis, angina or heart troubles, cancer, chronic lung disease, diabetes, digestive problems, high blood pressure, osteoporosis, Parkinson disease, peripheral vascular disease and stroke. The total number of comorbidities was then calculated. We measured the presence of multisite pain over the last 6 weeks using an adapted version of the Nordic Pain Questionnaire..$^{24,25}$ Participants reported if they have experienced pain in 6 different body sites (neck, shoulders, elbows, hands/wrist, hips, knees, feet/ankles).

\section{Other descriptive variables}

The EQ5D-5L was used to measure health related quality of life. ${ }^{26}$ Responses from the five domains (pain, mobility, self-care, usual activities, and anxiety and depression) were converted into a single EQ-5D index value using the EQ-5D-5L Crosswalk Index Value Calculator to produce a final QoL value. ${ }^{27}$ Participants also completed the Clock Drawing Test which is a nonverbal test of cognitive function used in primary care to screen for cognitive impairment. ${ }^{28}$. Participants were asked to draw the face 
of a clock depicting the time "10 after 11". There is a 6-point scoring system and participants with a score of 4 or below were classified as having reduced cognitive function.

\begin{abstract}
Statistical analysis
Descriptive statistics were used to summarise the characteristics of participants. Modified Poisson and ordered logistic regression analyses were conducted to assess the relationship between BP groups (independent variable) and adverse health states (dependent variables). Models were adjusted for demographic, lifestyle factors, comorbidities and multi-site pain. We used multiple imputation by chained equations to handle missing data (see supplementary Text S1 and Table S1). ${ }^{29,30}$ A complete case analysis was also performed to understand the impact of missing data on the findings. Data analysis was performed using Stata software version 15.1 (StataCorp, College Station, Texas).
\end{abstract}

\title{
Results
}

\section{Participants' characteristics}

The mean age of participants was $75 \pm 6.8$ years. Over half of the participants reported BP with $33.7 \%$ $(1,786 / 5,304)$ reporting BP only, $11.2 \%(n=594 / 5,304)$ reporting BP and NC and $8.3 \%(n=441 / 5,304)$ reporting BP and non-NC leg pain (Figure 1). Only the prevalence of BP and NC increased with age. BP was more common in females and those reporting more comorbidities (Table 1). Those with leg pain reported poorer health behaviours (smoked more, higher BMI), lived in more deprived areas, reported lower education levels and a greater proportion reported doing more physically demanding work. Participants with BP had lower quality of life across all domains of the EQ5D-5L compared to participants without BP. Quality of life was poorest in those with BP and NC. The majority of participants cohort presented with high cognitive function with $85 \%$ ( $n=4544 / 5304)$ having a score of 5 or 6 on the Clock Drawing Test. There was slightly higher prevalence of reduced cognitive function in participants with leg pain. 


\section{Back pain symptom presentation}

The age of onset was similar across BP groups. Around $30 \%$ of participants reported that their BP started 25 years ago or more (Table 2). Those with leg pain reported more frequent BP than participants only reporting BP. A report of pain on most/every day was most common amongst those with NC (Table 2). Participants with NC reported the highest ratings of pain troublesomeness. Very few reported improving symptoms since onset and, most commonly, symptoms fluctuated over time. The proportion of participants reporting persistent pain or pain getting worse since onset was highest in those with NC.

\section{Adverse health states}

Fifty-five percent of participants $(2,937 / 5,304)$ reported at least one adverse health state (Table 1$)$.

The most common adverse health states reported were a fall in the last year $(29 \% ; 1,534 / 5,304)$ and being frail $(27 \% ; 1,433 / 5,304)$. Urinary incontinence was the least commonly reported $(10 \%$; $534 / 5,304)$. Confidence to walk half a mile was generally high amongst the cohort with the exception of those reporting NC. Across the three BP groups, there was a greater prevalence of all adverse health states compared to those with no BP and this increased further among those who reported leg pain and highest amongst those with NC. Participants with BP reported more adverse health states than without BP. Those with NC had the greatest proportion of participants reporting two or more adverse health states. When two or more adverse health states were reported $(1,661 / 5,304)$, the most three most commonly reported combinations were 1 ) having a fall in the last year and mobility decline $(6.8 \%, 113 / 1,661), 2)$ being frail and mobility decline $(6.7 \%, 111 / 1,661)$ and 3$)$ being frail, mobility decline and a fall in the last year $(6.3 \%, 105 / 1,661)$

After adjusting for demographics, lifestyle factors, comorbidities and multi-site pain, all BP groups were associated with the adverse health states studied (Table 3). For all the adverse health states, 
there was an increase in the strength of association with the addition of leg pain. This was particularly noticeable in participants with NC where we observed the strongest associations with frailty (RR 95\% Cl 1.88 [1.67-2.11]), mobility decline ( $R R$ 95\% Cl 1.74 [1.54-1.97]), low walking confidence ( $R R$ 95\% Cl 3.11 [2.56-3.78]), and falls (RR 95\% Cl 1.42 [1.25-1.61]) compared to no BP. The association with poor sleep quality was similar for both types of leg pain while incontinence was greater in those with nonNC leg pain.

\section{Complete case analyses}

This study had a small amount of missing data (see supplementary Text S1 and Table S1). Similar effect estimates were obtained from the complete case analyses compared to those obtained using imputed data (Table S2).

\section{Discussion}

$\mathrm{BP}$ is very common in older adults with approximately half of the participants reporting BP in the last 6 weeks which is higher than previously reported in UK cohorts. ${ }^{1,2}$ To the best of our knowledge, this is the first study conducted in England to report on the prevalence of back related leg pain in community dwelling older adults. The total prevalence of leg pain (20\%) was similar to that reported within community dwelling cohorts in the USA ${ }^{12}$ and the prevalence of NC $(11 \%)$ was similar to that reported in other countries ${ }^{5,31,32}$ For many, BP was long-standing and few reported an improving clinical picture especially those NC. There was a consistent pattern of worse health with the report of leg pain. Those reporting NC had the most severe and frequent BP, worst quality life, more comorbidities and the greatest prevalence of adverse health states. This finding is consistent previous research by Battie et. al. who describes a very substantial burden of illness associated with a diagnosis of lumbar spinal stenosis. ${ }^{33}$ Hicks et. al. also found back and leg pain to be associated with increased risk of falls and functional difficulties and those with leg pain were worst affected. ${ }^{12}$ 
Few studies have compared the impact of distinct patterns of leg pain. This study demonstrates that

those with NC were most greatly affected by the majority of adverse health states studied after adjusting for demographic, lifestyle factors, comorbidities and pain at other joints. The biggest difference observed was in mobility related adverse health states (mobility decline and low walking confidence) suggesting that older adults reporting NC are more likely to have poor mobility. Maintaining mobility is integral to retaining active independence in later life and is a priority for older adults. ${ }^{34,35}$

Mobility is also central to the model of frailty as conceptualised by Fried. ${ }^{35}$ This model describes the features of frailty as slow speed walking, low physical activity, poor grip strength, unintentional weight loss and self-reported exhaustion..$^{35}$ It is unsurprising that the factors related to poor mobility were most strongly associated with NC, as worsening symptoms with walking is a typical presentation. $^{3}$

Frailty and falls were a significant problem for many participants with back and leg pain. Both of which have a substantial impact on the individual and, with an ageing population, an increasing burden on health and care services. The report of adverse health outcomes was common amongst participants and one-third reported more than one so there is potentially some overlap between adverse health states. Based on the Fried Model of frailty, several of the adverse outcomes are conceptually linked within this model. Frail older adults have less capacity to deal with illness or injury making them vulnerable and more likely to experience falls, disability, mobility decline, hospitalisation and the need for nursing home care ${ }^{36}$. One in three adults over the age of 65 years will fall each year and fall related injuries costs the NHS around $£ 2.3$ billion annually. ${ }^{37}$ Poor sleep quality was associated with leg pain and this may contribute to self-reported exhausted which features in the Fried Frailty Model. ${ }^{35}$.

Incontinence was the final adverse health state associated with back and leg pain. An association with BP has been reported previously. ${ }^{38}$ Incontinence is a common precipitant to care home 
admission so can affect an older person's ability to maintain their indepdendence. ${ }^{39}$ There are many

causes of incontinence in older adults but pain can affect pelvic muscle function and inability to mobilise safely to the toilet may also contribute..$^{40}$

\section{Implications}

These findings highlight the impact of BP and leg pain in older age and their association with adverse health states which are a growing problem with an ageing population. ${ }^{41}$ Back and leg pain are potentially modifiable symptoms that could be targeted to reduce adverse health states in older adults. Treatments for back and leg pain are effective for some people but more effective treatments are needed. Current treatments predominantly focus on symptom reduction but it is possible that treatments which also target the broader impact of ageing and focus on addressing frailty, declining mobility and falls alongside symptomatic treatments will be of greater benefit to older adults. We would also suggest that measuring age-related adverse outcomes in trials of treatments would also increase understanding of the impact of current treatments on these important health outcomes for older outcomes.

\section{Strengths and potential limitations}

The strength of this study is the large sample size with a small amount of missing data. We used multiple imputation to minimize selection bias and to increase precision. ${ }^{30}$ We have also compared the OPAL cohort to other community-based cohorts to assess representativeness to the general population. This included the English Longitudinal Study of Ageing cohort and our cohort is broadly similar in regards to sex, age and work status. ${ }^{42}$

A limitation of the study is that it is a cross-sectional analysis so we cannot conclude causality. Future longitudinal analysis of the OPAL cohort data is planned to better understand causality. Data collection used postal questions so we were reliant on self-report of symptoms. This may have resulted in some participants being misclassified as BP may exist alongside other conditions such as vascular claudication which have a similar symptom presentation. This study also focused on the clinical 
syndrome of neurogenic claudication rather than a diagnosis of spinal stenosis based on radiological evidence so the prevalence of anatomical spinal stenosis is unknown in the cohort. We used a selfreported measure of frailty which may over estimate frailty compared to using physical performance measures ${ }^{43}$ but the prevalence of frailty in this study was similar to other cohorts using a measure of self-report. ${ }^{44}$ We also collected limited data related to psychosocial factors that are known to influence pain and disability. The Tilberg Frailty Indicator does include questions on anxiety, depression, ability to cope, social support and loneliness. However, we did not use construct specific questionnaires to measure these constructs and we did not measure constructs such catastrophising or fear avoidance. We have not investigated the influence of these psychosocial factors on the relationship between NC and adverse health outcomes for older people. Finally, the proportion of participants reporting cognitive impairment was low so these findings may under represent those living in the community with severe cognitive impairment.

\section{Conclusion}

Back and leg pain is a common problem for older community-dwelling adults and associated with reduced quality of life and adverse health states including frailty, falls and mobility decline. Participants with NC were particularly affected suggesting that developing more effective treatments for older adults with NC is of upmost importance and have the potential to impact on broader health outcomes.

\section{Acknowledgments}

The authors would like to thank the individuals who participated in The Oxford Pain, Activity and Lifestyle (OPAL) cohort study and the GP practices across England for assisting with the identification of eligible patients. 


\section{References}

1. Macfarlane GJ, Beasley M, Jones EA, et al. The prevalence and management of low back pain across adulthood: results from a population-based cross-sectional study (the MUSICIAN study). Pain 2012;153:27-32.

2. Docking RE, Fleming J, Brayne C, et al. Epidemiology of back pain in older adults: prevalence and risk factors for back pain onset. Rheumatology (Oxford) 2011;50:1645-53.

3. Suri P, Rainville J, Kalichman L, et al. Does this older adult with lower extremity pain have the clinical syndrome of lumbar spinal stenosis? JAMA 2010;304:2628-36.

4. Deyo RA, Mirza SK, Martin BI, et al. Trends, major medical complications, and charges associated with surgery for lumbar spinal stenosis in older adults. JAMA 2010;303:1259-65.

5. Jensen RK, Jensen TS, Koes B, et al. Prevalence of lumbar spinal stenosis in general and clinical populations: a systematic review and meta-analysis. Eur Spine J 2020.

6. Dobbs R, May S, Hope P. The validity of a clinical test for the diagnosis of lumbar spinal stenosis. Manual Therapy 2016;25:27-34.

7. Leveille SG, Bean J, Ngo L, et al. The pathway from musculoskeletal pain to mobility difficulty in older disabled women. Pain 2007;128:69-77.

8. Leveille SG, Jones RN, Kiely DK, et al. Chronic musculoskeletal pain and the occurrence of falls in an older population. JAMA 2009;302:2214-21.

9. Eggermont LH, Shmerling RH, Leveille SG. Tender point count, pain, and mobility in the older population: the mobilize Boston study. J Pain 2010;11:62-70.

10. Shega JW, Dale W, Andrew M, et al. Persistent pain and frailty: a case for homeostenosis. J Am Geriatr Soc 2012;60:113-7.

11. Makris UE, Fraenkel L, Han L, et al. Restricting back pain and subsequent mobility disability in community-living older persons. J Am Geriatr Soc 2014;62:2142-7.

12. Hicks GE, Gaines JM, Shardell M, et al. Associations of back and leg pain with health status and functional capacity of older adults: findings from the retirement community back pain study. Arthritis Rheum 2008;59:1306-13.

13. Gobbens RJ, van Assen MA, Luijkx KG, et al. The Tilburg Frailty Indicator: psychometric properties. Journal of the American Medical Directors Association 2010;11:344-55.

14. Gobbens RJ, van Assen MA, Luijkx KG, et al. Determinants of frailty. Journal of the American Medical Directors Association 2010;11:356-64.

15. Newell AM, VanSwearingen JM, Hile E, et al. The modified Gait Efficacy Scale: establishing the psychometric properties in older adults. Physical therapy 2012;92:318-28.

16. Lamb SE, Jorstad-Stein EC, Hauer K, et al. Development of a common outcome data set for fall injury prevention trials: the Prevention of Falls Network Europe consensus. J Am Geriatr Soc 2005;53:1618-22.

17. Collin C, Wade DT, Davies S, et al. The Barthel ADL Index: a reliability study. International disability studies 1988;10:61-3.

18. Gompertz P, Pound, P., \& Ebrahim, S. A postal version of the Barthel Index. Clinical Rehabilitation, 8(3), 233-239. Clinical Rehabilitation 1994;8:233-9.

19. Buysse DJ, Reynolds CF, 3rd, Monk TH, et al. The Pittsburgh Sleep Quality Index: a new instrument for psychiatric practice and research. Psychiatry research 1989;28:193-213.

20. Parsons S, Carnes D, Pincus T, et al. Measuring troublesomeness of chronic pain by location. BMC Musculoskelet Disord 2006;7:34.

21. de Schepper El, Overdevest GM, Suri P, et al. Diagnosis of Lumbar Spinal Stenosis: An Updated Systematic Review of the Accuracy of Diagnostic Tests. Spine (Phila Pa 1976) 2013;38:E469-E81.

22. Department for Communities and Local Government. The English Indices of Deprivation 2015. In. London: Department for Communities and Local Government 2015.

23. Guralnik JM, Fried LP, Simonsick EM, et al. The Women's Health and Aging Study: Health and Social Characteristics of Older Women with Disability. Bethesda, MD: National Institute of Aging, 1995. 
24. Kuorinka I, Jonsson B, Kilbom A, et al. Standardised Nordic questionnaires for the analysis of musculoskeletal symptoms. Appl Ergon 1987;18:233-7.

25. Parsons S, Breen A, Foster NE, et al. Prevalence and comparative troublesomeness by age of musculoskeletal pain in different body locations. Fam Pract 2007;24:308-16.

26. Herdman $M$, Gudex $C$, Lloyd $A$, et al. Development and preliminary testing of the new fivelevel version of EQ-5D (EQ-5D-5L). Qual Life Res 2011;20:1727-36.

27. van Hout $B$, Janssen MF, Feng YS, et al. Interim scoring for the EQ-5D-5L: mapping the EQ-5D5L to EQ-5D-3L value sets. Value Health 2012;15:708-15.

28. Pinto E, Peters R. Literature review of the Clock Drawing Test as a tool for cognitive screening. Dement Geriatr Cogn Disord 2009;27:201-13.

29. Janssen KJ, Donders AR, Harrell FE, Jr., et al. Missing covariate data in medical research: to impute is better than to ignore. Journal of clinical epidemiology 2010;63:721-7.

30. Sterne JA, White IR, Carlin JB, et al. Multiple imputation for missing data in epidemiological and clinical research: potential and pitfalls. BMJ (Clinical research ed.) 2009;338:b2393.

31. Miyakoshi N, Hongo M, Kasukawa $\mathrm{Y}$, et al. Prevalence, Spinal Alignment, and Mobility of Lumbar Spinal Stenosis with or without Chronic Low Back Pain: A Community-Dwelling Study. Pain Res Treat 2011;2011:340629.

32. Ishimoto Y, Yoshimura N, Muraki S, et al. Prevalence of symptomatic lumbar spinal stenosis and its association with physical performance in a population-based cohort in Japan: the Wakayama Spine Study. Osteoarthritis Cartilage 2012;20:1103-8.

33. Battié MC, Jones CA, Schopflocher DP, et al. Health-related quality of life and comorbidities associated with lumbar spinal stenosis. Spine J 2012;12:189-95.

34. Troutman-Jordan M, Staples J. Successful aging from the viewpoint of older adults. Research and theory for nursing practice 2014;28:87-104.

35. Fried LP, Tangen CM, Walston J, et al. Frailty in older adults: evidence for a phenotype. J Gerontol A Biol Sci Med Sci 2001;56:M146-56.

36. Clegg A, Young J, Iliffe S, et al. Frailty in elderly people. Lancet 2013;381:752-62.

37. National Institute of Health and Care Execellence. NICE CG161: Falls: assessment and prevention of falls in older people. 2013.

38. Cassidy T, Fortin A, Kaczmer S, et al. Relationship Between Back Pain and Urinary Incontinence in the Canadian Population. Phys Ther 2017;97:449-54.

39. Morrison A, Levy R. Fraction of Nursing Home Admissions Attributable to Urinary Incontinence. Value in Health 2006;9:272-4.

40. Spencer M, McManus K, Sabourin J. Incontinence in older adults: The role of the geriatric multidisciplinary team. British Columbia Medical Journal 2017;59.

41. Gale CR, Cooper C, Sayer AA. Prevalence of frailty and disability: findings from the English Longitudinal Study of Ageing. Age Ageing 2015;44:162-5.

42. Steptoe A, Breeze E, Banks J, et al. Cohort profile: the English longitudinal study of ageing. International journal of epidemiology 2013;42:1640-8.

43. Collard RM, Boter $\mathrm{H}$, Schoevers RA, et al. Prevalence of frailty in community-dwelling older persons: a systematic review. J Am Geriatr Soc 2012;60:1487-92.

44. Arnadottir SA, Bruce J, Lall R, et al. The importance of different frailty domains in a population based sample in England. BMC Geriatr 2020;20:16. 
Table 1. Characteristics of the cohort according to back pain groups

\begin{tabular}{|c|c|c|c|c|c|}
\hline \multirow[b]{2}{*}{ Characteristics } & \multirow[b]{2}{*}{$\begin{array}{l}\text { Overall } \\
(N=5,304)\end{array}$} & \multirow[b]{2}{*}{$\begin{array}{c}\text { No BP } \\
(n=2,483)\end{array}$} & \multicolumn{3}{|c|}{ Back pain groups } \\
\hline & & & $\begin{array}{l}\text { BP only } \\
(n=1,786)\end{array}$ & $\begin{array}{c}\text { BP + non-NC } \\
\text { leg pain } \\
(n=441)\end{array}$ & $\begin{array}{l}B P+N C \\
(n=594)\end{array}$ \\
\hline Age (years), mean (SD) & $74.9(6.8)$ & $74.8(6.8)$ & $74.7(6.6)$ & $74.4(6.6)$ & $76.2(7.2)$ \\
\hline \multicolumn{6}{|l|}{ Sex, n (\%) } \\
\hline Male & $2,584(48.7)$ & $1,329(53.5)$ & $816(45.7)$ & 185 (41.9) & $254(42.8)$ \\
\hline Female & $2,720(51.3)$ & $1,154(46.5)$ & $970(54.3)$ & $256(58.1)$ & $340(57.2)$ \\
\hline \multicolumn{6}{|l|}{ Education, n (\%) } \\
\hline Higher education & $1,889(35.6)$ & $922(37.1)$ & $657(36.8)$ & $130(29.5)$ & $180(30.3)$ \\
\hline Secondary & $2,990(56.4)$ & $1,392(56.1)$ & $1,004(56.2)$ & $258(58.5)$ & $336(56.6)$ \\
\hline None or primary & $393(7.4)$ & $159(6.4)$ & $117(6.6)$ & $44(10.0)$ & $73(12.3)$ \\
\hline \multicolumn{6}{|c|}{ Occupational physical demands, n (\%) } \\
\hline Light & $1,429(26.9)$ & $719(29.0)$ & $487(27.3)$ & $108(24.5)$ & $115(19.4)$ \\
\hline Moderate & $2,481(46.8)$ & $1,181(47.6)$ & $857(48.0)$ & $195(44.2)$ & $248(41.8)$ \\
\hline Strenuous & $1,354(25.5)$ & $568(22.9)$ & $429(24.0)$ & $132(29.9)$ & 225 (37.9) \\
\hline \multicolumn{6}{|l|}{ IMD category, n (\%) } \\
\hline C1 - Most affluent & $2,980(56.2)$ & $1,417(57.1)$ & $1,053(59.0)$ & $217(49.2)$ & $293(49.3)$ \\
\hline C2 & $1,512(28.5)$ & $712(28.7)$ & $491(27.5)$ & 139 (31.5) & $170(28.6)$ \\
\hline C3 & $436(8.2)$ & $217(8.7)$ & $121(6.8)$ & $40(9.1)$ & $58(9.8)$ \\
\hline C4 - Most deprived & $376(7.1)$ & $137(5.5)$ & $121(6.8)$ & $45(10.2)$ & $73(12.3)$ \\
\hline BMI, mean (SD) & $26.6(4.9)$ & $26.2(4.6)$ & $26.4(4.7)$ & $27.2(5.1)$ & $28.5(5.8)$ \\
\hline \multicolumn{6}{|l|}{ Smoking, n (\%) } \\
\hline Never & $2,640(49.8)$ & $1,288(51.9)$ & $880(49.3)$ & 199 (45.1) & $273(46.0)$ \\
\hline Ex-/Current & 2,649 (49.9) & $1,193(48.1)$ & $900(50.4)$ & $239(54.2)$ & $317(53.4)$ \\
\hline Multisite pain (0-7), median (IQR) & $2(1-3)$ & $1(0-2)$ & $2(1-3)$ & $3(1-4)$ & $3(2-5)$ \\
\hline $\begin{array}{l}\text { Comorbidities (0-11), median } \\
\text { (IQR) }\end{array}$ & $2(1-2)$ & $1(1-2)$ & $2(1-2)$ & $2(1-3)$ & $2(1-3)$ \\
\hline Reduced cognitive function, $\mathrm{n}(\%)$ & $760(14.3)$ & 349 (14.1) & 224 (12.5) & $88(20.0)$ & $99(16.7)$ \\
\hline $\begin{array}{l}\text { EQ-5D crosswalk index value, } \\
\text { mean (SD) }\end{array}$ & $0.77(0.20)$ & $0.85(0.16)$ & $0.76(0.18)$ & $0.65(0.25)$ & $0.59(0.23)$ \\
\hline \multicolumn{6}{|l|}{ Adverse health states } \\
\hline Poor sleep quality, n (\%) & $1,035(19.5)$ & $327(13.2)$ & $340(19.0)$ & $150(34.0)$ & $218(36.7)$ \\
\hline Urinary incontinent, n (\%) & $534(10.1)$ & $168(6.8)$ & 177 (9.9) & $73(16.6)$ & $116(19.5)$ \\
\hline $\begin{array}{l}\text { Confidence to walk }(1-10)^{\ddagger}, \\
\text { median (IQR) }\end{array}$ & $1(1-3)$ & $1(1-1)$ & $1(1-3)$ & $1(1-6)$ & $5(1-9)$ \\
\hline $\begin{array}{l}\text { Mobility decline over the last } \\
\text { year, } n(\%)\end{array}$ & $1,350(25.5)$ & $431(17.4)$ & $425(23.8)$ & $159(36.1)$ & $335(56.4)$ \\
\hline Fall in the last year, $\mathrm{n}(\%)$ & $1,534(28.9)$ & $562(22.6)$ & $520(29.1)$ & $177(40.1)$ & $275(46.3)$ \\
\hline Frail, n (\%) & $1,433(27.0)$ & $387(15.6)$ & $487(27.3)$ & 198 (44.9) & $361(60.8)$ \\
\hline
\end{tabular}




\begin{tabular}{|c|c|c|c|c|c|}
\hline $\begin{array}{l}\text { Number of adverse health states } \\
(0-6) \text {, median }(I Q R)^{\#}\end{array}$ & $1(0-2)$ & $0(0-1)$ & $1(0-2)$ & $2(0-3)$ & $2(1-4)$ \\
\hline \multicolumn{6}{|l|}{$\begin{array}{l}\text { Number of adverse health states, } \\
\mathrm{n}(\%)\end{array}$} \\
\hline None & $2,209(41.7)$ & $1,317(53.0)$ & $706(39.5)$ & $110(24.9)$ & $76(12.8)$ \\
\hline One & $1,276(24.1)$ & $599(24.1)$ & $475(26.6)$ & $94(21.3)$ & $108(18.2)$ \\
\hline 2 or more & $1,661(31.3)$ & $503(20.3)$ & $559(31.3)$ & $212(48.1)$ & $387(65.2)$ \\
\hline
\end{tabular}

$\mathrm{NC}=$ neurogenic claudication; IMD=Index of Multiple Deprivation; $\mathrm{BMI}=$ body mass index; IQR= Interquartile range; $\mathrm{SD}=$ Standard Deviation; ${ }^{\ddagger}$ Scores were inverted, therefore, higher score is worse outcome; "participants rating their confidence to walk at 9-10/10 were categorised as having low walking confidence. 
Table 2. Symptom presentation amongst participants with back pain

\begin{tabular}{|c|c|c|c|c|}
\hline \multirow[b]{2}{*}{$\begin{array}{l}\text { Back pain } \\
\text { symptoms }\end{array}$} & \multirow{2}{*}{$\begin{array}{l}\text { All } \\
\text { participants } \\
\text { with back } \\
\text { pain } \\
(\mathrm{N}=\mathbf{2 , 8 2 1 )}\end{array}$} & \multicolumn{3}{|c|}{ Back pain groups } \\
\hline & & $\begin{array}{l}\text { BP only } \\
(n=1,786)\end{array}$ & $\begin{array}{l}\text { BP + non-NC leg } \\
\text { pain }(n=441)\end{array}$ & $\begin{array}{l}B P+N C \\
(n=594)\end{array}$ \\
\hline \multicolumn{5}{|l|}{ Age at onset of BP, n (\%) } \\
\hline$\leq 40$ years old & $886(31.4)$ & $571(32.0)$ & $144(32.7)$ & $171(28.8)$ \\
\hline 41-64 years old & $1,035(36.7)$ & $644(36.1)$ & $163(37.0)$ & $228(38.4)$ \\
\hline $65-74$ years old & $567(20.1)$ & $360(20.2)$ & $90(20.4)$ & $117(19.7)$ \\
\hline $75+$ years old & $300(10.6)$ & $191(10.7)$ & $40(9.1)$ & $69(11.6)$ \\
\hline \multicolumn{5}{|l|}{ BP frequency, $\mathrm{n}(\%)$} \\
\hline Rarely/few days & $821(29.1)$ & $702(39.3)$ & $69(15.7)$ & $50(8.4)$ \\
\hline Some days & $748(26.5)$ & $494(27.7)$ & $140(31.8)$ & $114(19.2)$ \\
\hline Most days/Every day & $1,216(43.1)$ & $567(31.8)$ & $227(51.5)$ & $422(71.0)$ \\
\hline \multicolumn{5}{|l|}{$\begin{array}{l}\text { BP Troublesome (intensity), } n \\
\text { (\%) }\end{array}$} \\
\hline Not at all/Slightly & $1,456(51.6)$ & $1,140(63.8)$ & $180(40.8)$ & $136(22.9)$ \\
\hline Moderate & $897(31.8)$ & $493(27.6)$ & $160(36.3)$ & $244(41.1)$ \\
\hline Very or extreme & 449 (15.9) & $145(8.1)$ & $97(22.0)$ & $207(34.9)$ \\
\hline \multicolumn{5}{|l|}{ BP pattern since onset, $\mathrm{n}(\%)$} \\
\hline Getting better & $86(3.1)$ & $66(3.7)$ & $11(2.5)$ & $9(1.5)$ \\
\hline Getting worse & $255(9.0)$ & $70(3.9)$ & $50(11.3)$ & $135(22.7)$ \\
\hline Fairly constant & $619(21.9)$ & $293(16.4)$ & $126(28.6)$ & $200(33.7)$ \\
\hline Comes and goes over time & $1,832(64.9)$ & $1,338(74.9)$ & $249(56.5)$ & $245(41.3)$ \\
\hline
\end{tabular}


Table 3. Cross-sectional association between back and leg pain and adverse health states compared to no back pain.

\begin{tabular}{|c|c|c|c|c|c|c|}
\hline Age related adverse & $\begin{array}{c}\text { Poor Sleep } \\
\text { Quality }\end{array}$ & $\begin{array}{c}\text { Urinary } \\
\text { Incontinence }\end{array}$ & $\begin{array}{l}\text { Confidence to } \\
\text { walk }^{\ddagger}\end{array}$ & Mobility decline & $\begin{array}{c}\text { Falls in previous } \\
\text { year }\end{array}$ & Frail \\
\hline & RR (95\%Cl) & RR (95\%Cl) & RR (95\%Cl) & RR (95\%Cl) & $\operatorname{RR}(95 \% \mathrm{Cl})$ & $\operatorname{RR}(95 \% \mathrm{Cl})$ \\
\hline No BP & 1.00 (Reference) & 1.00 (Reference) & 1.00 (Reference) & 1.00 (Reference) & 1.00 (Reference) & 1.00 (Reference) \\
\hline BP only & $1.17(1.02-1.35)$ & $1.17(0.95-1.43)$ & $1.23(1.06-1.43)$ & $1.13(1.00-1.26)$ & $1.14(1.03-1.26)$ & $1.38(1.24-1.54)$ \\
\hline $\mathrm{BP}+$ non-NC leg pain & 1.68 (1.41-1.99) & 1.59 (1.22-2.07) & 1.89 (1.52-2.36) & $1.42(1.22-1.64)$ & $1.40(1.22-1.61)$ & $1.77(1.55-2.02)$ \\
\hline $\mathrm{BP}+\mathrm{NC}$ & 1.67 (1.42-1.97) & 1.43 (1.12-1.83) & $3.11(2.56-3.78)$ & 1.74 (1.54-1.97) & 1.42 (1.25-1.61) & 1.88 (1.67-2.11) \\
\hline
\end{tabular}

Each regression model was adjusted for demographic (age, sex, occupational physical demands, education and are deprivation), lifestyle factors (body mass index and smoking status), comorbidities and multi-site pain. Multiple imputation was performed. Ten completed datasets were generated.

$\mathrm{RR}=$ Relative Risk; $\mathrm{BP}=$ back pain; $\mathrm{NC}=$ neurogenic claudication; $\mathrm{RR}=$ Relative Risk; $\mathrm{Cl}=$ confidence interval

${ }^{\ddagger}$ Range: 1 to 10 where higher score means lower level of confidence walking. 
Figure Legends

\section{Figure Legends}

Figure 1. Prevalence of back pain with and without leg pain by age groups 
$\% 60$

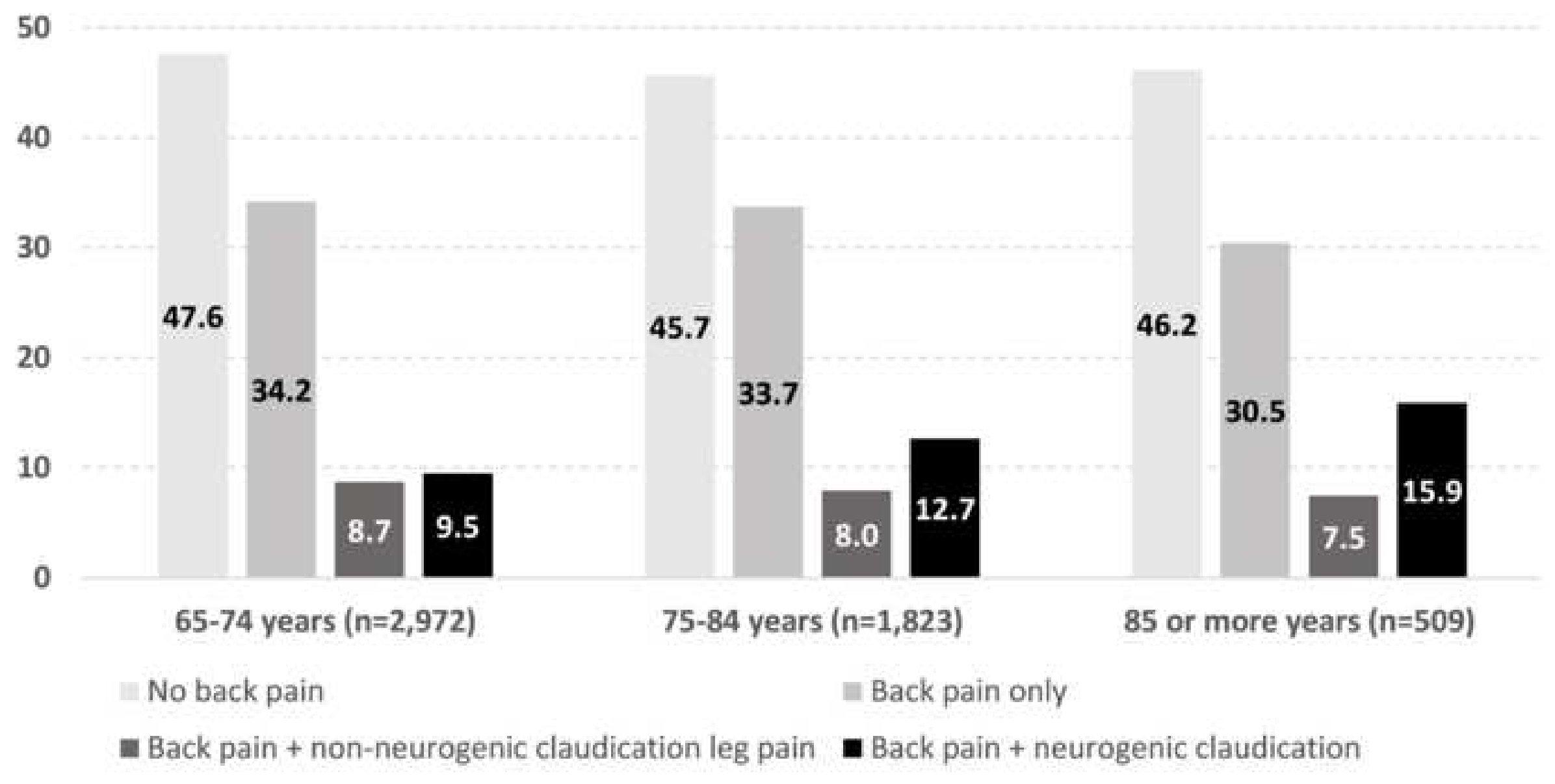


Click here to access/download Supplemental Data File (doc., pdf., xls., etc.) Supplemental Data File_28MAY2020.docx 